\title{
FABRICATION AND CORROSIVE PERFORMANCE EVALUATION OF CERIA ZIRCONIUM
}

\author{
Kalaiselvan $\mathbf{P}^{\mathbf{1}}$, Kamalakkannan $\mathbf{A}^{\mathbf{2}}$ \\ ${ }^{1}$ Assistant Professor, Department of Mechanical Engineering, Knowledge Institute of Technology, Tamilnadu, India. \\ ${ }^{2}$ Assistant Professor, Department of Mechanical Engineering, Knowledge Institute of Technology, Tamilnadu, India.
}

\begin{abstract}
Oxidations at elevated temperatures results in the degradation of materials in land based gas turbines, aircraft, marine and in industrial applications. Now hot corrosion is recognized as a severe problem in the fuel based power producing systems around the globe. The hot corrosion and erosion are responsible for huge losses in boilers and associated components. A clear knowledge about this problem guides us to develop suitable protective system to maximize the utilization of such components. This problems can be solved either by changing materials or altering environment or by separating material surface from the environment. The use of coatings for separating materials from environment for preventing the hot corrosion gaining importance in surface engineering .The plasma spray coatings of yttria stabilized zirconium coatings provides good resistance to the stainless steels, high speed steels and other materials to withstand optimum corrosion and wear properties. Further addition of the ceria to the zirconium results with greater corrosion resistance.
\end{abstract}

Keywords: Plasma arc coating of ceria zirconium oxide, corrosion resistance of ceria zirconium.

$* * *$

\section{INTRODUCTION}

The economic cost of corrosion is enormous, and has been estimated that, the $40 \%$ of steel production goes to replace corroded parts and the products. In addition to that, there are also indirect costs associated with plant shut down and lower efficiency of equipment. Super alloys have been developed for high temperature applications, but they are not able to meet the requirements of high temperature strength, high temperature erosion and corrosion resistance simultaneously. Erosion is a serious problem in many engineering systems, including steam and jet turbines, pipelines and valves used in slurry transportation matter and fluidized bed combustion systems. The protection of metals or alloys against corrosion and wear can be achieved by development and the use of better corrosion and wear resistant thermal spray coatings. These corrosion and wear resistant coatings can add value to products by allowing the mechanical properties of the substrate materials to be maintained while protecting them against wear or corrosion. Thermal barrier coatings (TBCs) have been developed to protect metallic and silica based ceramic components in turbine for high temperatures. Thermal Barrier Coatings are employed in the field such marine turbines and power plant boilers where a very high life time and corrosion resistance are required. TBCs consists of a duplex structure of nickel chromium is used as a bond coat and the mixture of yttria stabilized zirconium and cerium oxide in some proportion is used as a top coat material. The bond coat is given through either atmospheric plasma spray or high velocity oxy-fuel technique, and the top coat is deposited by means of atmospheric plasma coating here the yttria stabilized zirconium and cerium oxide combined together with the output of very greater corrosion resistance.

\section{EXPERIMENTAL PROCEDURE}

Stainless steel is taken as a specimen material. Different samples of varying size were taken for analysis. The samples with dimensions are shown in Figure 3.2.The metallic substrate should be treated before coating. The substrate is usually covered with grease that protects the surface against corrosion. The grease was removed in the cleaning process. Cleaned pieces are shaped in order to obtain desired dimensions to avoid sharp angles that are difficult to be coated. The remaining area other than the area to be coated was covered with 'masks' during spraying. At last, immediately prior to the deposition process, the surface has to be activated. Without activation, the coating would not adhere to the substrate surface. Activation by abrasive grit blasting, i.e. roughening, is the most frequently applied process nowadays. Degreasing of new metal substrates was done by using organic solvent acetone. The process was carried out in a clean room and the remaining liquid was carefully recycled. Every care was taken to protect the operator from hazardous exposure. The substrates need to be shaped in order to meet the dimensional specifications. A little material has to be removed in the places where the coating is to be deposited. Shaping is also necessary to avoid sharp angles or sharp ends where it is difficult to spray a coating or, on the other hand, where adherence to the substrate is poor. The adherence becomes lower because of the high concentration of thermal stresses inside the coatings sprayed in such places. Substrate shaping was done by wire cutting method. 
Table 2.1 Process parameters for abrasive grit blasting

\begin{tabular}{|l|l|}
\hline Parameters & Values \\
\hline Grit size (Alumina) & $940-1905$ microns \\
\hline Grit size (sand) & $63-203$ microns \\
\hline Operating Pressure & $8 \mathrm{bar}$ \\
\hline Blasting time & $45 \mathrm{~min}$ \\
\hline Nozzle diameter & $2.38 \mathrm{~mm}$ \\
\hline
\end{tabular}

Over coat is provided above the bond coat with suitable combination of powder materials. The powder materials that have been selected are cerium oxide,yttria stabilized zirconium. Mixing of powder with some combination selected as per the property we need to improve in the coating. So from the study of previous works we came to know $25 \%$ of cerium in the coating gives improved corrosive property. I wish to fabricate the coating with $30 \%$ of cerium in combination. So mixing should be done as per our required combination of mixture. By using the chemical balance out of $100 \mathrm{~g}$ we have to add the materials $30 \%$ cerium oxide, $8 \%$ yttrium oxide, and $62 \%$ zirconium oxide to contribute all together to form $100 \mathrm{~g}$.

Chemical combination of coating materials:

$$
\mathbf{3 0} \% \mathrm{CeO}_{2}+8 \% \mathrm{Y}_{2} \mathrm{O}_{3}+62 \% \mathrm{ZrO}_{2}
$$

A bond coating of NiCoCrAlY was used in thermal-barrier coatings. The bond coating was sprayed by plasma spray process. An improvement in oxide coating adhesion can be achieved by the application of bond coatings. The first layer of the coating is called the bond coat. It enables the coating to bond over the substrate and therefore plays an integral role in forming a thermal barrier.

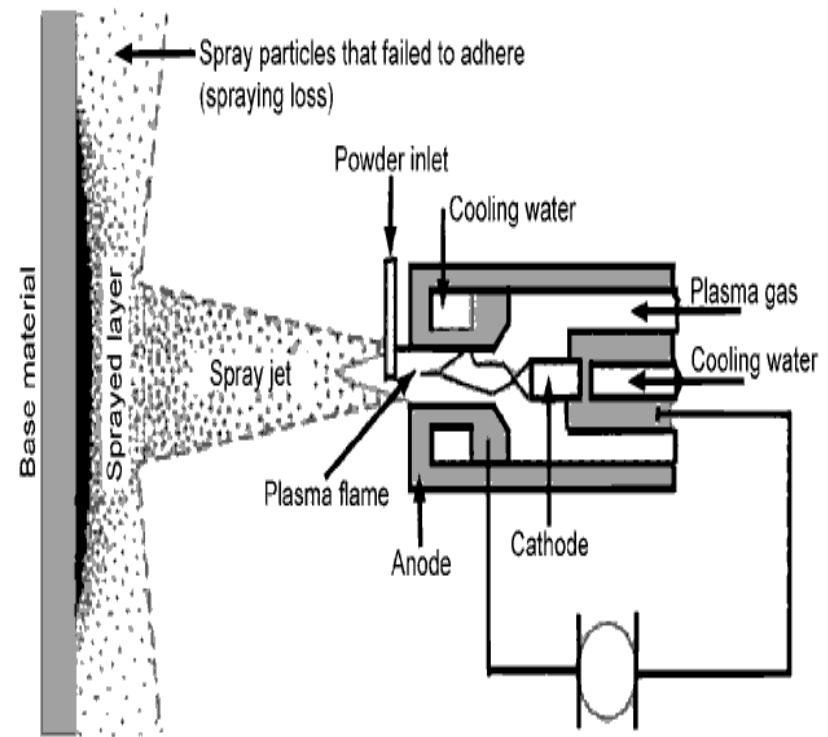

Fig 2.1 Plasma spray coating setup

Among the different coating systems, the plasma spray process is commonly used to protect the hardware operating in high temperature environments, such as combustor liners and gas turbine blades, from excessive high heat fluxes and temperatures [36]. Plasma spraying uses metal in powder form. The ceramic coating system is shown in Figure 3.7. The coating materials in the form of a powder is passed into a plasma jet in which powder particles are melted and accelerated towards the surface to be coated. The powder particles, approximately 50 micrometers in diameter, are accelerated and melted in the flame on their high speed 200 $\mathrm{m} / \mathrm{sec}$ path to the substrate, where they impact and undergo rapid solidification.

Table 2.2 Plasma Spray Operating Parameters

\begin{tabular}{|l|l|}
\hline \multicolumn{2}{|l|}{ Operating Parameters } \\
\hline Plasma Gun & $3 \mathrm{MB}$ Gun, $40 \mathrm{~kW}$ \\
\hline Inert gases & Argon, Hydrogen \\
\hline \multirow{2}{*}{ Flow Rate } & Argon :- 80- 90 LPM \\
\cline { 2 - 2 } & Hydrogen:- 15 to 18 LPM \\
\hline
\end{tabular}

The technical specification of plasma spray gun is $3 \mathrm{MB}$ gun for a typical dc torch operating at $40 \mathrm{~kW}$ with Metco MN plasma spray system and GH Nozzle with arc current of 500 Amps and Arc voltage of 70 Volts. Argon was used as the primary gas at a flow rate of 80 - 90 LPM and hydrogen was used as the secondary gas at a flow rate of $15-18$ LPM. The distance between the nozzle and the substrate was kept as $80 \mathrm{~mm}$.

\section{RESULTS AND DISCUSSIONS}

\subsection{Plasma Spray Composition}

Plasma spray is used to form deposits of $250 \mu \mathrm{m}$ of Zirconia Ceria powder with composition of Ceria as follows

1) $30 \% \mathrm{CeO}_{2}+8 \% \mathrm{Y}_{2} \mathrm{O}_{3}+62 \% \mathrm{ZrO}_{2}$

As per the literature survey, $250 \mu \mathrm{m}$ is the optimum thickness for turbine blades.

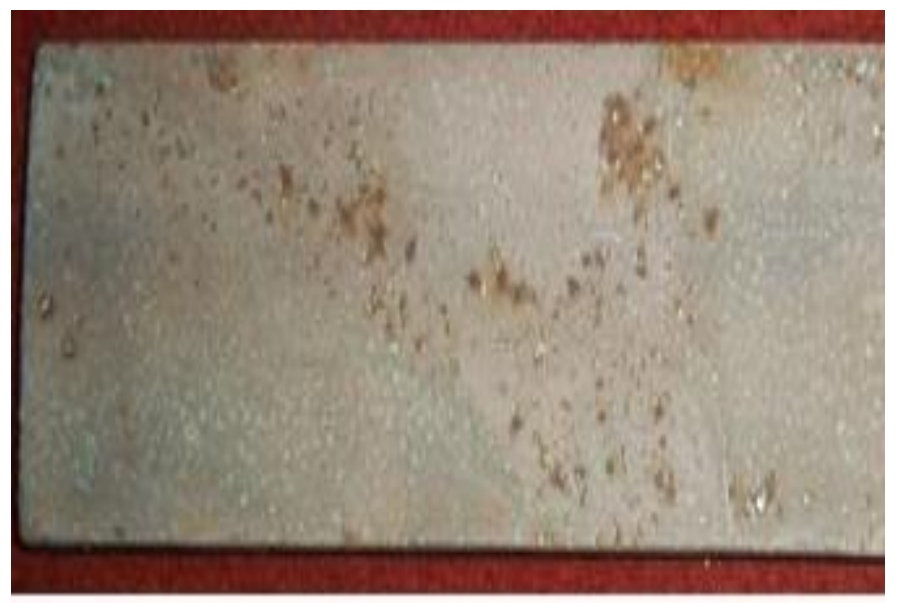

Fig 3.1 Zirconia Ceria Powder $\left(8 \% \mathrm{Y}_{2} \mathrm{O}_{3}+67 \% \mathrm{ZrO}_{2}+25 \%\right.$ $\mathrm{CeO}_{2}$ ) coated samples after salt spray test (358 hours) 


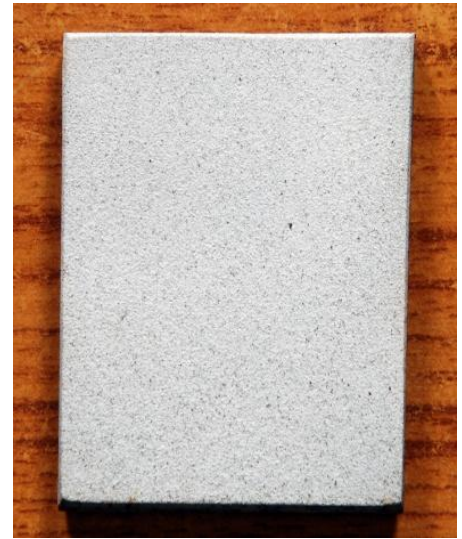

SPECIMEN BEFORE TEST

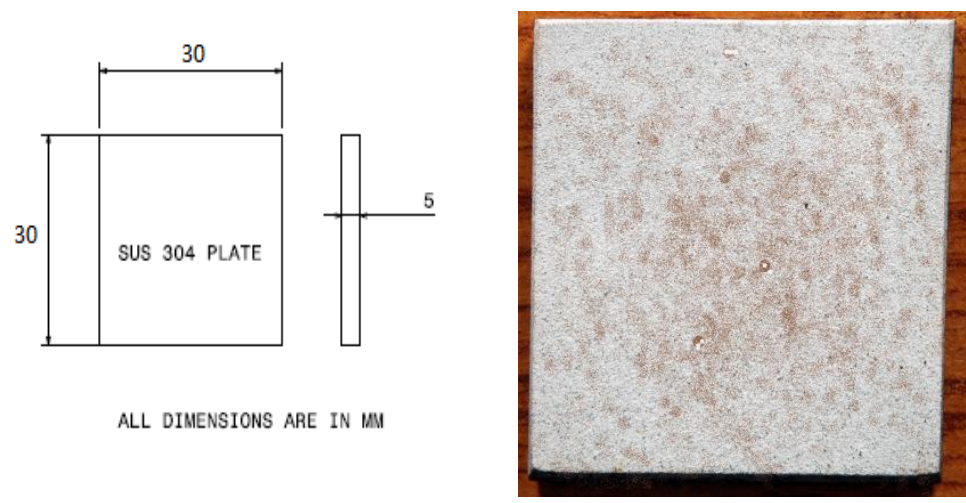

SPECIMEN AFTER TEST(396 hours)

Fig 3.2 Rectangular Specimen before and after testing (Zirconia Ceria powder $\left(30 \% \mathrm{CeO}_{2}+8 \% \mathrm{Y}_{2} \mathrm{O}_{3}+62 \% \mathrm{ZrO}_{2}\right)$

\subsection{Results}

Table 3.1 Test Results

\begin{tabular}{|l|l|l|l|}
\hline Percentage Of Ceria In The Sample & $20 \%$ & $25 \%$ & $30 \%$ \\
\hline Time For Minute Red Rust Occurrence & 320 hours & 358 hours & 396 hours \\
\hline Weight Of The Coating Material Removed & $0.623 \mathrm{~g}$ & $0.521 \mathrm{~g}$ & $0.41 \mathrm{~g}$ \\
\hline
\end{tabular}

The material stainless steel (grade 304) coated with above composition is subjected to salt spray corrosion test. The test has to be done upto the red rust begins to appear on the surface of the coating sample since all tests done on the coating material with $20 \%$ cerium coated sample and $25 \%$ cerium coated sample are tested upto the time when it shows the red rust. The time for red rust occurrence in the $20 \%$ and $25 \%$ are 320 hours and 358 hours respectively. The coating sample consists of $30 \%$ of cerium is placed in the testing equipment which should be covered in all the other sides with the insulated tape. The sample is placed in the testing equipment which consists of condition such as $\mathrm{Ph}$ solution, air pressure, concentration of sodium chloride, solution discharge per hour, chamber temperature as per ASTM standards. After the beginning of the test the sample has to be noted at every one hour time gap. The red rust began to appear in the sample after 396 hours(17 days). The result obtained has been studied very clearly. From the previous test results it has been concluded that the percentage increase in the cerium oxide is the cause for the improved resistance to corrosion. so the $5 \%$ increase in the cerium oxide content increases the life of the coating against the corrosive destruction. Comparatively $30 \%$ cerium oxide sample withstand longer than the $25 \%$ cerium oxide sample.

\section{CONCLUSION}

In this work, Zirconia Ceria powder coatings were deposited by Atmospheric Plasma Spray process on 304 grade stainless steel. The coating thickness was taken as $250 \mu \mathrm{m}$ since it is the optimum coating thickness for turbine blades. NiCoCrAlY was used as a bond coat. Plasma spray process was used to form deposits of the Zirconia Ceria powder $\left(30 \% \mathrm{CeO}_{2}+8 \% \mathrm{Y}_{2} \mathrm{O}_{3}+62 \% \mathrm{ZrO}_{2}\right)$. Salt spray test has been done on the material to find the corrosive resistive property of the coating material enriched with cerium content. So $30 \%$ cerium alloyed coating sample withstands longer than $25 \%$ cerium alloyed coating sample.

\section{REFERENCES}

[1] Deepa mudgal, Surendrasingh, Satyaprakash (2012), "High Temperature cyclic oxidation behavior of Ni and Co based superalloys", Journal of minerals and materials characterization and Engineering, Vol.11, No.3, pp.211-219.

[2] Vikas Chawla, Amita Chawla, Puri D, Prakash S, Prema G, Gurbuxani, Buta Singh Sindhu, (2011), "Hot corrosion and erosion problems in coal based power plants in India and possible solutions - A Review", Journal of minerals and materials characterization and Engineering, Vol.10, No.4, pp.367-385

[3] Mark F Mooser, (1990), "Metallic ceramic coatings as replacements for cadmium plating", 26th annual aerospace/ airlineplating and metal finishing forum and exposition, Vol 1990, pp.1-6.

[4] Herbert Herman, Sanjay Sampath, Robert McCune, (2011), "Thermal spray: current status and future trends", Materials research society,Vol.25, Issue 7, pp.17-25.

[5] Hathaipat Koiprasert, Panadda Nirantlumpong, (2007), "Sealing of thermally sprayed stainless steel coatings against corrosion using nickel electroplating technique", Songklanakarin Journal of science and technology,29(4), pp.1029-1038.

[6] Nichollos J.R, Pereira V, Lawson K J,Rickerby D S (1998), "Process control of deposition profiles in the manufacture of EB-PVD thermal barrier 
coatings", Intelligent processing of high performance materials, pp.161 - 173 .

[7] Vasile Hotea, Irina Smical, Elena Pop, Lozsef Juhasz, Gabriel Badescu (2008), "Thermal spray coatings for modern technological applications", Fascicle of management and technological Engineering,Vol.7(17), pp.1486-1493.

[8] Vijaysingh B Suryawanshi, Inamdar K.H, (2012), "Method of surface roughness evaluation using Ruby Laser Beam", International journal of engineering research and applications, Vol. 2, Issue 3, pp.1512-1515.

[9] Anees U Malik, Shahreer Ahmad, Ismaeel Andijani (1999), "Corrosion behavior of steels in gulf seawater environment", Desalination, Vol. 123, pp.205-213.

[10] Kanchana Trakulcoo, (1987), “Accelarated corrosion testings: Salt spray Test", Asean journal of science and technology, Vol.4, Issue.1, pp.5568 .

[11] Kennedy D.M, Hashmi M.S.J, (1998), "Methods of wear testing for advanced surface coatings and bulk materials", Journal of materials processing technology 77, pp.246-253.

[12] Gun Y Lee, Dharan C. K.H, Ritchie R .O, (2003), "A physically-based abrasive wear model for composite materials", Wear 252, pp.322-331

[13] Brinksmeier E, Hannover, Cammett J.T, Cincinnati, Konig W, (1982), "Residual stresses measurement and causes in machining processes", Annals of the CIRP Vol. 31, Issue.2, pp.491-510.

[14] Tamarin Y, (2002), "Protective coatings for turbine blades", ASM International, The materials information society, pp.21.

[15] Scrivani A, Rizzi G, Bardi U, Giolli C, Muniz Miranda M, Ciattini S, Fossati A, Borgioli F. (2007), "Thermal fatigue behavior of thick and porous thermal barrier coatings systems", Journal of thermal spray technology, Vol.16, Issue 5-6, pp.816-821.

[16] Kazuya Otsuka, Katsuyuki Matsunaga, Atsutomo Nakamura, Seiichiro Ii, Akihide Kuwabara, Takahisa Yamamoto, Yuichi Ikuhara (2004), "Effects of dislocations on the oxygen ionic conduction in yttria stabilized zirconia", Materials transactions, Vol.45, No.7, pp.2042 -2047.

[17] Chao Zhang, Wen-Ya Lia, Marie-Pierre Planche, Cheng-Xin Li, Hanlin Liao, Chang-Jiu Li, Christain Coddet, (2008), "Study on gas permeation behaviour through atmospheric plasmasprayed yttria stabilized zirconia coating", Surface \& coatings technology, Vol.202, pp.5055-5061.

[18] "Seria yttria stabilized zirconia oxide HOSP powder" METCO 205 NS

[19] Portinha A Teixeira V, Carneiro J, Martins J, Costa M.F, Vassen R Stoever D,(2005), "Characterization of thermal barrier coatings with a gradient in porosity", Surface coatings and technology, Vol.195, pp.245-251
[20] Kristina Brinkienwe, Romualdas Kezelis, Jurate Cesniene, Vladas Mecius, Audrius Zunda, (2008), "Characterization of wear properties of plasma sprayed ceramic coatings", material science, Vol.14, No.4, pp.345-349.

[21] Mahesh Chand, Aarti Mehta, Rina Sharma, Ojha V.N, Chaudhary K.P, (2011), "Roughness measurement using optical profiler with selfreference laser and stylus instrument - A comparative study", Indian journal of pure \& applied physics, Vol.49, pp.335-339.

[22] Zhenghao Gan, Heong Wah N.G, (2004), "Cyclic thermal shock behaviour on plasma sprayed graded coatings", Material science and engineering, Vol.385, Issues 1-2, pp.314-324

[23] Kezelis, R., Brinkiene, (2007),. "Wear Resistance of Plasma Sprayed Zirconia Coatings", Proccedings of Biotribology Workshop, ISBN: 978-84-932064-4-4, Fundation Tekniker, Eibar, Spain, pp. 81-85.

[24] Moskal G, (2007), "The porosity assessment of thermal barrier coatings obtained by APS method", Journal of achievements in materials and manufacturing systems, Vol 20, Issue 1-2, pp.483486.

[25] Bobzin K, Schlafer T, Richardt K, Bruhl M. (2008), "Friction and wear behavior of NiCoCrAlY and mixture of NiCoCrAlY and yttria partially stabilized zirconia", Journal of thermal spray technology, Vol. 12, Issue 4, pp.576-596.

[26] Menghani. J, Pai. K.B,. Totlani.M.K, Jalgoankar.N, (2010) Corrosion and Wear Behavior of $\mathrm{ZrN}$ Thin Films, Proceedings of the World Congress on Engineering, Vol.III, pp. 22-25.

[27] Dasappa Ramesh, Ragera Parameshwarappa Swamy, Tumkur Krishnamurthy Chandrashekar, (2012), "Corrosion behaviour of Al6061-frit particulate metal matrix composites in sodium chloride solution", Journal of minerals and materials characterization and engineering, Vol.1, pp.15-19.

[28] Saremi Mohsen, Afrasiabi Abbas, Kobayashi Akira, (2007), "Bond coat oxidation and hot corrosion behavior of plasma sprayed YSZ coating on Ni superalloy", Transactions of JWRI, Vol.36, No.1, pp.41-45.

[29] Dinesh Gond, Puri D, Prakash S, (2011), "Hot corrosion behaviour of yttria stabilised zirconia as plasma sprayed coated boiler steel in air and salt at $900^{\circ} \mathrm{C}$ under cyclic condition", Journal of minerals \& materials characterization \& engineering, Vol.10, No.5, pp.463-478. 